\title{
Anfíbios nos anos iniciais: estratégia didática envolvendo contos de fadas para o ensino de biologia básica
}

\author{
Amphibians in the early years: didactic strategy involving fairy tales \\ for teaching basic biology
}

\author{
Lucas Peres Guimarães lucaspegui@ hotmail.com \\ Doutorando do Instituto Federal de Educação Ciência e Tecnologia do Rio de Janeiro; Professor do \\ Colégio Espaço Verde \\ Jéssica Pereira Ribeiro jessicapribeiro@hotmail.com \\ Professora do Colégio Espaço Verde \\ Camila Ferraz Moreira Pereira camila.fmp.17@gmail.com \\ Professora do Colégio Espaço Verde
}

\begin{abstract}
Resumo: São inegáveis as contribuições e o interesse que os contos de fadas despertam nas pessoas das mais diversas idades. Na educação, essa atividade pode se tornar um recurso didático-pedagógico para potencializar a aprendizagem. Nesse sentido, o presente trabalho, que tem como destaque o conto de fadas "O Príncipe Sapo", objetivou realizar uma estratégia didática para abordar a temática sobre anfíbios em uma turma do $3^{\circ}$ ano do ensino fundamental de uma escola privada de Volta Redonda (RJ). Essa estratégia foi composta por uma abordagem inicial envolvendo propostas práticas, como a produção de desenhos relacionados à temática apresentada, ida ao laboratório para analisar a morfologia de um sapo, e, por fim, a modelagem dos membros inferiores dos anuros. Após a aplicação, foi realizada uma análise qualitativa da inserção do conto de fadas para o ensino de ciências nos anos iniciais. Ficou evidente que a realização de estratégias diferenciadas, pode promover resultados significativos, como uma melhor associação e assimilação dos conteúdos apresentados com o conhecimento prévio dos alunos, aumentando, dessa forma, a motivação e o interesse dos estudantes pela temática de anfíbios.
\end{abstract}

Palavras-chave: Ensino de Ciências, Príncipe Sapo, recurso didático pedagógico

Abstract: The contributions and interest that fairy tales arouse in people of different ages are undeniable. In education this activity can become a didactic-pedagogical resource to enhance learning. In this sense, the present work, which highlights the fairy tale "Príncipe Sapo" (Frog Prince), aimed at carrying out a didactic strategy to address the topic of amphibians in a 3rd grade class of a private school in Volta Redonda (RJ). This strategy was composed by an initial approach involving drawing, going to the laboratory to analyze the morphology of a frog and, finally, the modeling of the lower limbs of anurans. After the application, a qualitative analysis of the insertion of the fairy tale was performed for science teaching in the early years. It became evident that the insertion of differentiated strategies can promote a better association, motivation and interest of students in the amphibian theme.

Keywords: Science Education, Frog princess, pedagogical didactic resource

Recebido em: $13 / 04 / 2020$

Aceito em: 14/07/2020 


\section{INTRODUÇÃO}

Apesar do ensino de Ciências apresentar como principal objetivo a promoção de situações que favoreçam aos educandos a compreensão do mundo, e as relações que existem entre os seres vivos, muitos ainda possuem desinteresse e dificuldade de aprendizagem (ARRAIS, 2019). Grande parte dos educandos entende que estudar ciências "não passa de um conjunto de nomes a ser memorizado e não conseguem relacionar o que aprendem com a vida cotidiana" (ALBUQUERQUE, BRAGA; GOMES, 2012, p. 59).

O ensino de zoologia é, na maioria das vezes, baseado na memorização de termos técnicos e sem contextualização ou abordagem da fauna local (SILVA et al., 2007). A falta de tal relação, passa a impressão ao educando que a proteção e preservação dos animais não é sua responsabilidade, ocasionando falta de identidade e significado durante o estudo da biodiversidade integrante do ambiente ao qual pertence (SANTOS; PINHEIRO; RAZERA, 2012). Desse modo, é importante que os educadores de Biologia reformulem e/ou estabeleçam novos critérios e objetivos para o maior interesse do estudo, propondo estratégias pedagógicas que vislumbrem o ensino tanto das características morfológicas dos seres vivos, quanto das relações dinâmicas que esses estabelecem quando estão no meio ambiente (SANTOS; PINHEIRO; RAZERA, 2012).

Trabalhos recentes da autora Arrais (2019, p. 43), mostram-nos alternativas para transformar a realidade do ensino de zoologia em sala de aula. "De acordo com a percepção dos estudantes, em relação aos recursos, o jogo didático mostrou-se como um instrumento que promoveu a diversão, interação, motivação e a busca pelo conhecimento para a maioria dos participantes". Devido a essa boa prática, esse trabalho buscará inserir o lúdico da mesma maneira. Contudo, nos anos iniciais do Ensino Fundamental.

Entre os vertebrados, os anfíbios são um dos grupos mais afetados pela ação antrópica, o que tem ocasionado nas últimas décadas, um enorme declínio das suas populações (HOF et. al, 2011). Sabendo que o declínio desses animais está relacionado à ação do homem, é necessário que o ensino de Biologia sensibilize os educandos 
quanto à importância desses animais para a natureza (CAIRO; ZALBA; NEBBIA, 2010).

Os anfíbios são importantes dentro das cadeias alimentares, pois participam do equilíbrio ecológico. Isso porque esses animais controlam a proliferação de insetos e servem de alimento para outros seres. Estudos recentes sugerem também, que eles são indicadores da qualidade ambiental e são alvos de pesquisas sobre a produção de fármacos empregando toxinas presentes na sua pele (SANTOS; LUCAS; CARASEK, 2011).

Apesar da sua importância ambiental e farmacológica, os anfíbios sofrem ainda um preconceito por parte das pessoas, as quais adotam posturas que não contribuem para a preservação e ainda disseminam meios para o seu extermínio, favorecendo a sua extinção (KINDEL; WORTMANN; SOUZA, 1997).

É por esse motivo, que esse trabalho propõe uma estratégia didática aos discentes do ensino fundamental, a fim de formar estudantes que possam intervir de modo positivo nos diversos contextos que estão inseridos.

Existem trabalhos da mesma natureza na literatura, dentre os quais pode-se destacar o trabalho de Arrais (2019). Como pontuado anteriormente, este trabalho que apresentamos, corrobora com os objetivos do trabalho citado. No entanto, apresenta uma proposta nos anos iniciais do ensino fundamental que carece de maior atenção na área de Ensino de Ciências.

Sendo assim, este trabalho teve como objetivo desenvolver ações didáticas lúdicas sobre anfíbios, para diferenciar a sua morfologia e reconhecer a sua relevância como importantes sujeitos do equilíbrio ambiental. A presença do caráter lúdico pode proporcionar momentos de desenvoltura e motivação, favorecendo a interação social e criando condições necessárias para estabelecer a aprendizagem na busca de efeitos positivos. Os alunos do $3^{\circ}$ ano do Ensino Fundamental, apresentam grande curiosidade para os estudos dos animais e, além disso, esse estudo é componente curricular da disciplina de Ciência.

\section{PROCEDIMENTOS METODOLÓGICOS}

Este trabalho é uma pesquisa qualitativa, sendo as interpretações dos autores levadas em conta na análise e no desenvolvimento da estratégia didática. Tal Recebido em: 13/04/2020 
procedimento gera um conhecimento mais aprofundado de um fenômeno, as dimensões complexas de um problema ou tema, envolvendo um número restrito de participantes (BARBATTO, 2008, p. 16).

Para a estratégia pedagógica, foi usado o modelo didático das patas dos sapos, pererecas e rãs, feito com massa de modelar, e o conto de fadas "O Príncipe sapo". O uso do primeiro, deve-se ao fato de que os estudantes do $3^{\circ}$ ano se interessam mais significativamente por propostas concretas e palpáveis, resultando na ampliação da curiosidade dos educandos acerca do conteúdo apresentado.

O trabalho com os modelos de massa de modelar possibilita uma ação centrada no estudante com postura ativa, distanciando-se de práticas escolares tradicionais. Já o uso do conto de fadas, como por exemplo, "O príncipe Sapo", pode proporcionar aos alunos uma maior aproximação com esses animais, além de promover a imaginação, a fantasia e a ludicidade nas atividades. Assim, essas estratégias didáticas podem influenciar relevantemente a aprendizagem dos educandos.

Este estudo foi desenvolvido com 25 (vinte e cinco) estudantes de uma turma do $3^{\circ}$ ano do Ensino Fundamental de uma escola privada de Volta Redonda (RJ). A proposta foi dividida em etapas que foram realizadas durante duas aulas de quarenta e cinco minutos em duas semanas distintas. Na primeira intervenção, para uma sondagem inicial, os discentes foram levados ao laboratório de ciências para observarem um espécime de sapo ao lado de uma coroa de plástico, tendo em vista o objetivo da atividade de usar o conto de fadas como motivador. E em sequência, foi realizada uma roda de conversa inicial. A segunda intervenção foi um momento dialógico em relação à visão dos educandos sobre os anfíbios, e a sua importância ecológica, seguido de análise morfológica de um sapo. Posteriormente, foi realizada uma roda de conversa que relacionava os anfíbios e o conto de fadas "O Príncipe Sapo". Nessa roda de conversa, ficou estabelecido que eles assistiriam o filme "A princesa e o sapo" de 2009 da Walt Disney com os pais. Por fim, foi realizada a construção de um modelo morfológico dos membros inferiores dos sapos, pererecas e rãs. Os modelos foram confeccionados com massa de modelar. A Tabela 1 indica os objetivos, materiais e duração de cada etapa.

Quadro 1: Descrição das etapas da estratégia didática

\begin{tabular}{|l|l|l|l|}
\hline \multicolumn{1}{|r|}{ INTERVENÇÃO } & OBJETIVO & \multicolumn{1}{c|}{ DURAÇÃO } & \multicolumn{1}{|c|}{ MATERIAIS } \\
\hline $\begin{array}{l}\text { Sapo e coroa de plástico } \\
\text { com roda de conversa }\end{array}$ & $\begin{array}{l}\text { Realizar uma } \\
\text { sondagem inicial da }\end{array}$ & 20 minutos & $\begin{array}{l}\text { Espécime de um sapo } \\
\text { Coroa de plástico }\end{array}$ \\
\hline
\end{tabular}

Recebido em: 13/04/2020

Aceito em: 14/07/2020 
Vol. 3, n. 5. Set./Dez.

ISSN: 2595- 4520

\begin{tabular}{|c|c|c|c|}
\hline & $\begin{array}{lcc}\text { relação } & \text { que } & \text { os } \\
\text { alunos faziam } & \text { do } \\
\text { sapo e a coroa } & \text { ao } \\
\text { conto de fadas. }\end{array}$ & & Diário de campo \\
\hline $\begin{array}{l}\text { Análise morfológica de } \\
\text { um sapo }\end{array}$ & $\begin{array}{l}\text { Reconhecer em um } \\
\text { espécime de sapo as } \\
\text { estruturas básicas } \\
\text { das características } \\
\text { dos anfíbios. }\end{array}$ & 25 minutos & $\begin{array}{l}\text { Espécime de um sapo } \\
\text { Pinça } \\
\text { Recipiente plástico } \\
\text { Luva } \\
\text { Diário de campo }\end{array}$ \\
\hline $\begin{array}{l}\text { Filme a princesa e o sapo } \\
\text { da Walt Disney (2009) }\end{array}$ & $\begin{array}{lr}\text { Proporcionar } & \text { um } \\
\text { momento } & \text { de } \\
\text { interação com } & \text { as } \\
\text { famílias em que os } & \text { aluos } \\
\text { alunos } & \\
\text { exemplificariam } & \text { o } \\
\text { que aprenderam na } \\
\text { escola durante um } \\
\text { momento } \\
\text { entretenimento. }\end{array}$ & Tarefa de casa & Filme \\
\hline $\begin{array}{l}\text { Roda de conversa sobre } \\
\text { o filme }\end{array}$ & $\begin{array}{lr}\text { Discutir } & \text { as } \\
\text { principais } & \\
\text { observações } & \\
\text { realizadas } & \text { no } \\
\text { momento } & \text { em } \\
\text { família } & \end{array}$ & 15 minutos & Diário de campo \\
\hline $\begin{array}{l}\text { Modelagem dos } \\
\text { membros inferiores dos } \\
\text { anuros }\end{array}$ & $\begin{array}{l}\text { Diferenciar o sapo, } \\
\text { a perereca e a rã a } \\
\text { partir de } \text { seus } \\
\text { membros inferiores, } \\
\text { por meio da } \\
\text { confecção desses } \\
\text { com massa de } \\
\text { modelar }\end{array}$ & 30 minutos & $\begin{array}{l}\text { Massa de modelar } \\
\text { Diário de campo }\end{array}$ \\
\hline
\end{tabular}

Fonte: Elaboração da pesquisa

Para a coleta de dados, foi utilizado diário de campo e registro dos alunos. Ao longo das aulas, os pesquisadores registravam algumas falas de estudantes nos diários de campo, além de outras observações consideradas pertinentes. Após a coleta de dados, os diários de campo foram organizados e analisados de acordo com os principais referenciais teóricos escolhidos (KISHIMOTO, 1997; SANTOS; PINHEIRO; RAZERA， 2012; ZALBA; NEBBIA， 2010; GUIMARÃES; FARIA， 2019). Posteriormente, realizada uma leitura e destacadas as falas significativas dos instrumentos, os estudantes foram denominados de A1 a A25 para que não fossem identificados. Por fim, ressalta-se que houve a autorização dos responsáveis dos alunos para que participassem da estratégia didática mencionada.

\section{DESENVOLVIMENTO DA ATIVIDADE E DISCUSSÃO}


A primeira etapa desta estratégia didática foi uma sondagem inicial. Os alunos, ao entrarem no laboratório de Ciências depararam-se com uma coroa de plástico e um espécime de sapo conservado em um recipiente de plástico apropriado. Os alunos foram indagados do que se lembravam ao ver esses dois objetos sobre a mesa. Rapidamente eles responderam: "o filme da princesa e o sapo”. Cabe ressaltar que a menção ao filme se deve a adaptação feita em 2009 pelos estúdios Disney, o qual, segundo relatos dos estudantes, foi assistido por todos. Portanto, houve muita motivação para que contassem o que ocorria no desenrolar das histórias.

Apesar dos discentes já terem assistido ao filme, consideramos válida, a estratégia de sugerir que vissem novamente. Esse fato favoreceu discussões mais interessantes no sentido de amplitude e complexidades delas, além de mais apropriadas para a idade e realidade dos alunos. A roda de conversa foi enriquecedora, pois grande parte da turma participou. Como consequência, verificou-se algum conhecimento sobre a biodiversidade dos anfíbios na fala inicial dos alunos, por exemplo, no relato de A08: “ $a$ princesa beijou o sapo e os estudantes relataram que ela virou uma rã’!

A partir dessa roda de conversa inicial, foi estruturada uma estratégia didática para a discussão da importância e o conhecimento dos anfíbios. Para relacionar com uma maior presença no cotidiano dos educandos, foram levados em conta o sapo, a perereca e a rã, já que se percebeu um pequeno equívoco por parte dos estudantes. Tendo em vista que afirmavam, anteriormente aos estudos, que a rã era a fêmea do sapo. Cabe ressaltar, no entanto, que essa "teoria" não foi compartilhada somente por uma aluna, uma vez que a maioria dos estudantes mencionou que o "sapo era macho e a rã era a fêmea". Portanto, diante desse reducionismo, decidimos explorar os anuros.

Em seguida, os estudantes participaram de um momento de interação em que expuseram algumas opiniões sobre os sapos, rãs e pererecas. Percebeu-se, que os educandos possuíam uma visão distorcida desses animais, uma vez que não sabiam sua importância ecológica e os relacionavam com algo nojento, como mencionado por A12: "Quando entra na minha casa um sapo pequeninho, eu tenho medo de grudar em mim"; essa fala foi complementada com outra de A22, que afirmou: “um dia entrou um sapo lá em casa e minha mãe gritou muito, eu nunca vi, mas minha mãe disse que é muito nojento". Outra fala que merece destaque, é a de A07 "me falaram que é só jogar sal se aparecerem que eles morrem".

Recebido em: $13 / 04 / 2020$

Aceito em: 14/07/2020 
Ficou evidente no momento das participações, que os estudantes não tinham um contato efetivo com os anuros. Tudo que sabiam era relativo ao que "ouviram falar". Ou seja, esses animais sofrem ainda um preconceito por parte das pessoas, as quais adotam posturas que não contribuem para a preservação, e ainda disseminam meios para o seu extermínio, favorecendo a sua extinção (KINDEL; WORTMANN; SOUZA, 1997). Devido a esse fato, foi levado um espécime de sapo e além de suas características morfofisiológicas. Foi estabelecido no momento da exposição, uma relação com a flora, e a importância ambiental dele, como por exemplo, o controle dos insetos.

Destaca-se que foram tomados os cuidados necessários no momento de visualização do anfíbio. Mesmo ressaltando a importância deles, foi enfatizado que alguns podem oferecer perigo.

Uma das principais preocupações ao propor qualquer atividade para os estudantes, é a de que o conhecimento não fique preso às paredes da escola. Ele precisa ganhar significado, caminhos para ser aplicado e em relação a conceitos científicos, é necessário que os alunos tenham um papel de divulgação da ciência que estão aprendendo na escola. Diante desses fatos, foi enviado para os seus responsáveis um comunicado para que esses conhecimentos chegassem ao contexto familiar:

Os contos de fadas despertam o interesse em qualquer idade. Você já imaginou aprender por meio de um conto de fadas? É muito importante para o processo de ensino-aprendizagem do seu filho, que o conhecimento seja lúdico e motivador. Por esse motivo, na aula de hoje, o $3^{\circ}$ ano aprenderá de forma contextualizada $e$ interdisciplinar sobre os anfíbios. Portanto, gostaríamos de convidá-los a participar desse momento de aprendizagem. Sugerimos como tarefa de casa e exercício de fixação, que contem a história "O Príncipe Sapo". Ou se preferirem, podem transformar essa atividade em um momento de entretenimento, e assistirem juntos ao filme da Walt Disney "A Princesa e o sapo." E, após, orientamos que discutam sobre os assuntos abordados, resultando em uma aprendizagem rica de autonomia $e$ protagonismo.

$\mathrm{Na}$ aula seguinte, foi perguntado aos alunos através de uma roda de conversa se assistiram ao filme ou leram o conto de fadas com o responsável. Os alunos haviam assistido ao filme, e o envolvimento das famílias se tornou evidente. Sendo assim, a rede de aprendizagem se tornou clara, quando os alunos relataram alguns diálogos ao 
assistirem ao filme com a família, como podemos citar: "O sapo vivia no brejo"; " $A$ cidade era muito úmida, ideal para sapos viverem; "Os sapos têm muco"; "A sua papada incha"; "Os sapos pulam muito"; "Gostam de pântano"; "sapos comem insetos"; "filhote do sapo é o girino". Todas essas informações foram relatadas pelos alunos e compartilhadas com seus responsáveis, tendo em vista que foram tratadas na aula anterior.

Para exemplificar diversidade dos anfíbios, e proporcionar um momento "mão na massa", os discentes foram convidados a produzirem modelos com massa de modelar, percebendo as diferenças existentes nos membros inferiores dos sapos, pererecas e rãs. Percebeu-se, portanto, que os estudantes ficaram motivados com esse momento. Pois além de ser uma oportunidade de contato com o docente para sanar as possíveis dúvidas e curiosidades individuais, a cooperação e interação entre os estudantes, foi de grande valia para a realização dessa atividade em grupo.

A modelagem proporcionou uma postura ativa dos estudantes, pois estiveram envolvidos na confecção a todo momento como protagonistas, visto que anteriormente eles só estavam escutando. Já com essa quebra de rotina, o envolvimento e a motivação aumentaram. E com isso, a opinião a respeito dos sapos foi se modificando. A08 afirmou: "nem é tão nojento quanto as pessoas falam", enquanto outros estudantes afirmaram que era, A17 afirmou; "Eu acho nojento, mas eu não vou querer que matem, pois eles são importantes".

A partir dessas falas, pôde-se perceber que os anuros começaram a ganhar mais importância no cotidiano dos saberes dos alunos, e que o conhecimento científico começou a interagir com as informações do senso comum. Desse modo, as opiniões dos educandos vão se formando constantemente, à medida que vão sendo estimulados, resultando em cidadãos conscientes com saberes significativos na sociedade. Contudo, é importante lembrar que a apresentação dessas espécies por meio de um conto de fadas, levou os alunos a uma postura mais atenta à importância do sapo, tendo em vista o protagonismo que ele exercia nessa história.

\section{CONSIDERAÇÕES FINAIS}

Mediante a estratégia didática realizada, foi possível não apenas identificar a lacuna existente no conhecimento em relação aos anfíbios, mas também, os medos e conhecimentos populares acerca dos sapos, pererecas e rãs. Nesse contexto, cabe ao 
Educador na área do Ensino de Ciências, procurar intervir com propostas educativas que sejam atrativas numa tentativa de alterar tal situação, visando, assim, preservar esses animais tão importantes ao ecossistema, mas tão pouco reconhecidos pelos seres humanos.

De acordo com a percepção dos estudantes em relação aos recursos, a inserção do conto de fadas mostrou-se como um instrumento que promoveu a diversão, interação, motivação e a busca pelo conhecimento para a maioria deles. Uma possibilidade que pode ser interessante para o meio educacional, é permitir que os educandos atuem como protagonistas e possam reconstruir contos de fadas que sejam próximos da área de Ciências, como forma de avaliação.

A partir das pesquisas e leituras realizadas para o desenvolvimento deste trabalho, também pôde-se verificar que há uma escassez em relação à produção de pesquisas e materiais que enfatizem os problemas encontrados no ensino de zoologia, especificamente na área dos anfíbios. Dessa maneira, é necessário que os docentes elaborem novos recursos e estratégias, de modo a contribuir para que essa área se torne mais significativa, contextualizada e dinâmica.

\section{REFERÊNCIAS}

ALBUQUERQUE, G. G.; BRAGA, R. P. S.; GOMES, V. Conhecimento dos alunos sobre microrganismos e seu uso no cotidiano. Revista de Educação, Ciências e Matemática, v.2, n.1, p. 58-68, 2012. Disponível em:< http://publicacoes.unigranrio.edu.br/index.php/recm/article/view/1913> Acesso em 08 de março de 2020

ARRAIS, A.A.M. Estudando os anfíbios: o jogo didático "Animazoo". Revista Eletrônica Ludus Scientiae, Foz do Iguaçu, v. 03, n. 01, p. 33-45, jan./jul. 2019. Disponível em: $<$ https://revistas.unila.edu.br/relus/article/view/1587/1741 > Acesso em 18 de abril de 2020

BARBAtTO, S. Metodologia de Pesquisa Qualitativa. Brasília: Editora UnB, 2008.

CAIRO, S. L.; ZALBA, S. M.; NEBBIA, A. J. Representaciones sociales acerca de los anfíbios em pastizales de Argentina. Su importancia para la conservación. Interciencia, v. $35, \quad$ n. $12, \quad$ p. 891-896. 2010. Disponível em:< http://periodicos.cfs.ifmt.edu.br/periodicos/index.php/rpd/article/view/573> Acesso em 20 de abril de 2020

GUIMARÃES, L.; FARIA, F. Química no Ensino Fundamental: estabelecendo conceitos por meio do estudo dos perfumes em uma formação continuada. Revista Insignare Scientia - RIS, v. 2, n. 2, p. 255-265, 19 set. 2019.

HOF, C.; ARAÚJO, M. B.; JETZ, W.; RAHBEK, C. Additive threats from pathogens, climate and land use for global amphibian diversity. Nature, 2011. p. N10650. Disponível em: $<$ https://periodicos.ufmg.br/index.php/rbpec/article/view/4248 $>$ Acesso em 20 de abril de 2020

KINDEL, E. A. I.; WORTMANN, M. L. C.; SOUZA, N. G. S. O estudo dos

Recebido em: 13/04/2020

Aceito em: $14 / 07 / 2020$ 
Vol. 3, n. 5. Set./Dez.

ISSN: 2595- 4520

vertebrados na escola fundamental. São Leopoldo: Unisinos, 1997. 130 p

KISHIMOTO, T.M. Jogo, brinquedo, brincadeira e a educação. São Paulo: Corte, 1997.

SANTOS, G. J. G.; PINHEIRO, U. S.; RAZERA, J. C. C. Ensino do Filo Porifera em região de espongiofauna: o ambiente imediato em aulas de Ciências. Revista Brasileira de Pesquisa em Educação em Ciências. v. 12, 2012. Disponível em:< https://pubmed.ncbi.nlm.nih.gov/22089134/ > Acesso em 20 de abril de 2020

SANTOS, M. P. V.; LUCAS, E. M.; CARASEK, F. L. Uma análise do ensino sobre anfíbios na educação básica. Revista Pedagógica, v. 2, 2011. Disponível em:< https://www.researchgate.net/publication/310837952_Uma_analise_do_ensino_sobre_a nfibios_na_Educacao_Basica > Acesso em 22 de abril de 2020

SILVA, R. M. L. S.; RABELO, D. S.; SILVA, L. F. G.; LEAL, M. V. C. O ensino da zoologia através do teatro de fantoches. Laboratório do Mundo: o Jovem e a Ciência. Salvador: Editora Universitária da UFBA, EDUFBA, 2007.

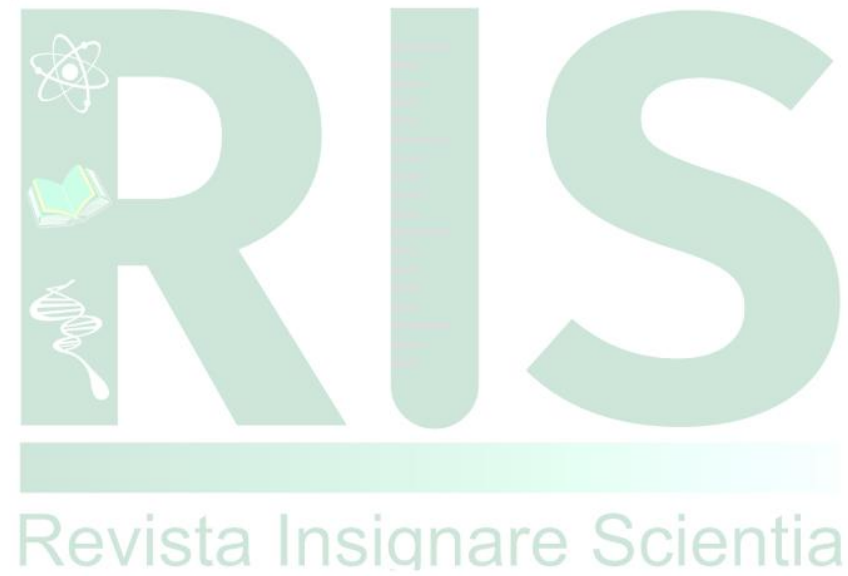

